\title{
Correction to: The role of diagnostic hysteroscopy in diagnosis of incomplete uterine septum/significant arcuate uterine anomaly in infertile patients in the era of transvaginal 3D ultrasound scan
}

\author{
O. Abuzeid ${ }^{1 *}$, J. LaChance ${ }^{2}$, O. Zaghmout ${ }^{1}$, J. Corrado ${ }^{3}$, J. Hebert ${ }^{1}$, M. Ashraf ${ }^{1,3,4}$ and M. I. Abuzeid ${ }^{1,3,4}$
}

Correction to: Middle East Fertility Society Journal 25, 1 (2020)

https://doi.org/10.1186/s43043-019-0009-7

Following publication of the original article [1], the authors would like to publish Figs. 4, 5, 6 with the correct values, which were missing.

The correct figures are given below.
Published online: 29 June 2020

Reference

1. Abuzeid et al (2020) Middle East Fertility Soc J 25:1. https://doi.org/10.1186/ s43043-019-0009-7

\begin{abstract}
Author details
${ }^{1}$ Department of Obstetrics and Gynecology, Hurley Medical Center and Michigan State University College of Human Medicine, Two Hurley Plaza, Ste 101, Flint Campus, Flint, MI, USA. 'Department of Research, Hurley Medical, Center and Michigan State University College of Human Medicine, Flint Campus, Flint, MI, USA. ${ }^{3}$ IVF Michigan Rochester Hills and Flint PC, Rochester Hills, MI, USA. ${ }^{4}$ Division of Reproductive Endocrinology and Infertility, Department of Obstetrics and Gynecology, Hurley Medical Center and Michigan State University College of Human Medicine, Flint Campus, Flint, $\mathrm{MI}, \mathrm{USA}$.
\end{abstract}

The original article can be found online at https://doi.org/10.1186/s43043019-0009-7.

* Correspondence: omabuzeid@gmail.com

The original article can be found online at https://doi.org/10.1186/s43043019-0009-7

${ }^{1}$ Department of Obstetrics and Gynecology, Hurley Medical Center and Michigan State University College of Human Medicine, Two Hurley Plaza, Ste 101, Flint Campus, Flint, MI, USA

Full list of author information is available at the end of the article
Springer Open (c) The Author(s). 2020 Open Access This article is licensed under a Creative Commons Attribution 4.0 International License, which permits use, sharing, adaptation, distribution and reproduction in any medium or format, as long as you give appropriate credit to the original author(s) and the source, provide a link to the Creative Commons licence, and indicate if changes were made. The images or other third party material in this article are included in the article's Creative Commons licence, unless indicated otherwise in a credit line to the material. If material is not included in the article's Creative Commons licence and your intended use is not permitted by statutory regulation or exceeds the permitted use, you will need to obtain permission directly from the copyright holder. To view a copy of this licence, visit http://creativecommons.org/licenses/by/4.0/. 


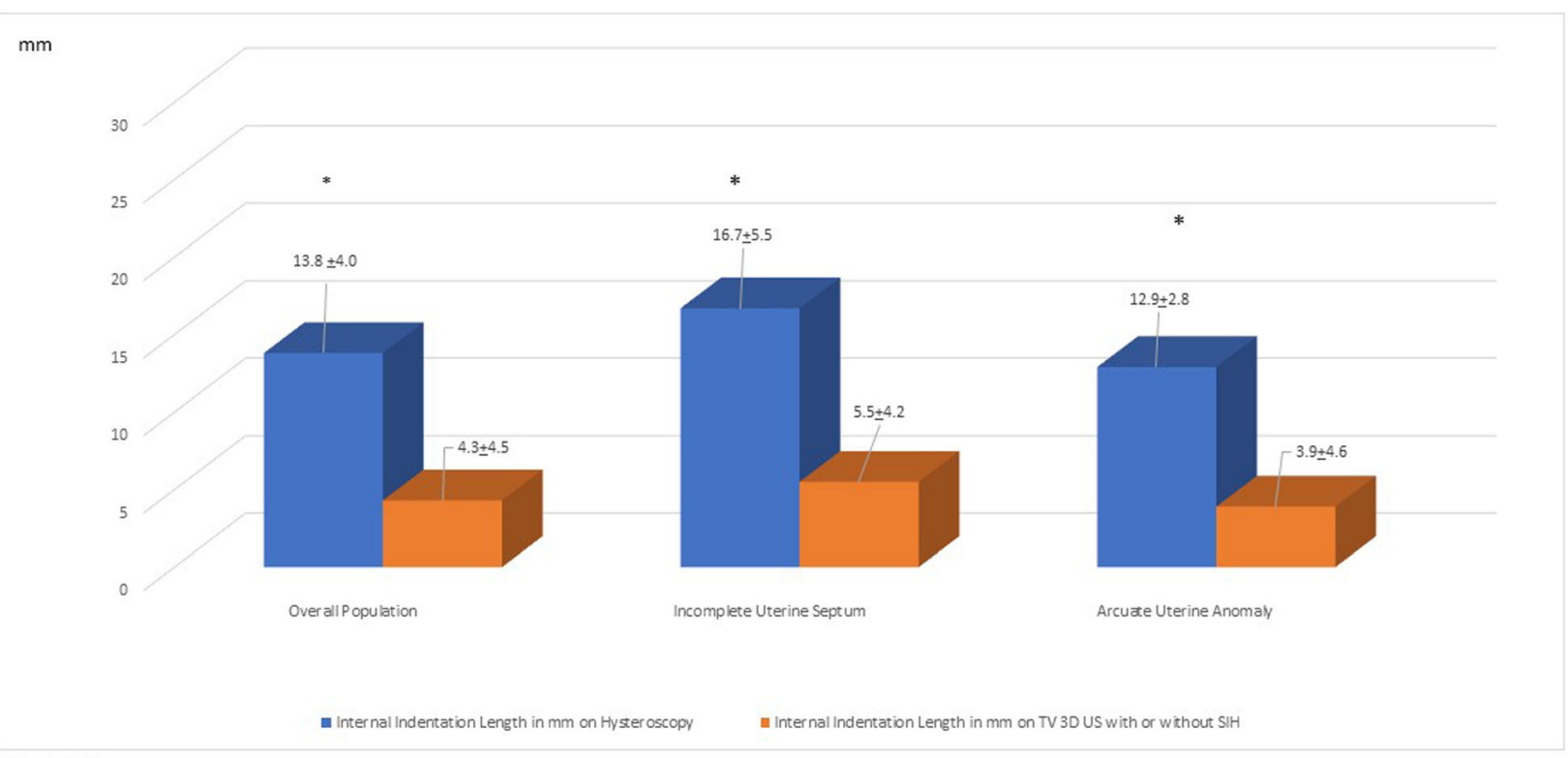

$* P<0.001$

Fig. 4 Comparison between the mean IILFM measured in millimeter on hysteroscopy and on TV 3D US with or without SIH, in patients with IUS, significant AUA, and in the overall population in all patients

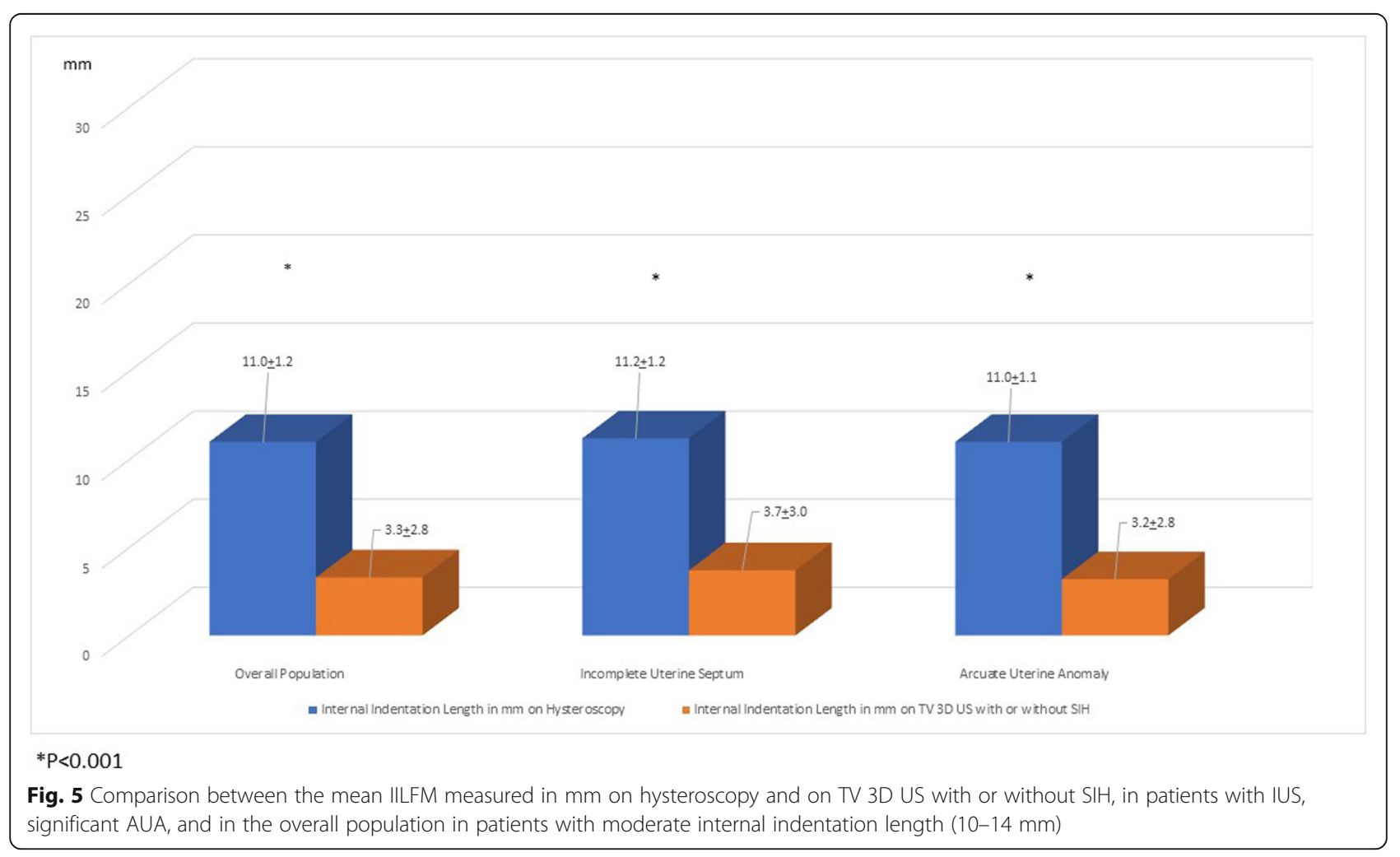




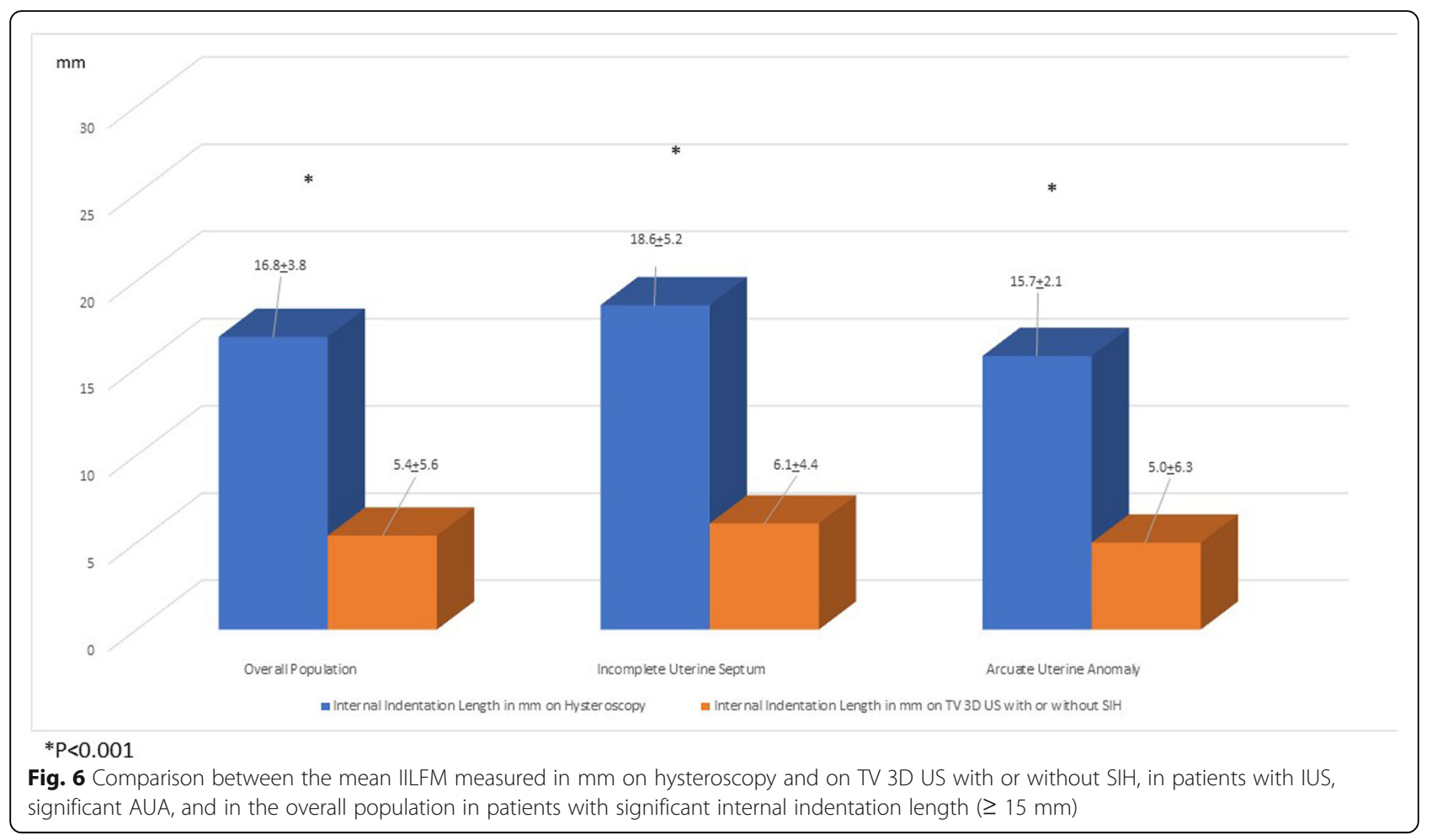

